Reprinted from The Review of Economics And Statistics Published for Harvard University by the North-Holland Publishing Company Copyright, 1984, by the President and Fellows

of Harvard College Vol. LXVI, No. 1, February, 1984

\title{
Formerly \# 375 THE REGULATION OF SURFACE FREIGHT TRANSPORTATION: THE WELFARE EFFECTS REVISITED
}

\author{
Ronald R. Braeutigam and Roger G. Noll*
}

\begin{abstract}
This paper reexamines a much-studied topic, the effects of surface freight regulation. It demonstrates that several studies use invalid methods to estimate the welfare costs of rate regulation, develops a correct procedure, and provides estimates of the welfare effects using data and modal market share relationships estimated by Boyer. The paper also analyzes some implications of the common assumption that the demand for total freight shipments by all modes is perfectly inelastic.
\end{abstract}

$\mathbf{N}$ UMEROUS studies have addressed the problem of estimating the costs of resource misallocation due to the regulation of surface freight transportation. Regulation creates inefficiency to the extent that it does not systematically relate prices to marginal costs. The theoretically correct method for estimating this inefficiency is to measure the loss in total surplus arising from the regulator's pricing policy.

Most of the early studies of the effects of regulation in this industry did not use this method, instead using the "comparative cost" approach." The latter assumes that modes are perfect substitutes. The cost of regulation is then estimated as the difference in shipping costs between the mode by which shipments are transported and the lowest cost mode.

More recent studies have used estimates of cross elasticities of demand to take account of the fact that most shippers do not regard transportation modes as perfect substitutes. ${ }^{2}$ Unfortunately, each of these studies adopts an approach that is not in general theoretically correct and that is likely to produce a biased estimate. Section I of this paper examines the methods for estimating welfare losses, and sections II and III use the data and econometric results in one paper, Boyer (1977), to calculate the magnitude of the bias from using incorrect methods. As is customary in these studies, we are ignoring other costs of regulation.

Received for publication November 21, 1981. Revision accepted for publication March 23, 1983.

${ }^{*}$ Northwestern University and California Institute of Technology, respectively.

The work reported here was supported financially by the Caltech Environmental Quality Laboratory. The authors would like to thank F. M. Scherer and E. Shin for helpful comments.

${ }^{1}$ See, for example, Peck (1965) and Harbeson (1969).

${ }^{2}$ See, for example, Moore (1975), Boyer (1977), Levin (1978), and Friedlaender and Spady (1980).

[ 80 ]

Replaces California Institute of Technology Social Science Working Paper \# 375

\section{Welfare Measurement in Interrelated Markets}

Let the tariffs for transporting a commodity be $p_{i}$ for mode $i, i=1,2$. The demand schedules for the two modes are assumed to be interdependent, and are written as $x_{i}\left(p_{1}, p_{2}\right)$. Let the marginal cost of transport service by mode $i$ be a constant $c_{i}$. Assuming that deregulation will lead to prices equal to marginal costs, the problem is to estimate the welfare effects of moving prices from $\left(p_{1}, p_{2}\right)$ to $\left(c_{1}, c_{2}\right)$.

If income effects are zero, a measure of the sum of consumer and producer surplus (e.g., total surplus) associated with the set of tariffs $\left(p_{1}^{\prime}, p_{2}^{\prime}\right)$ can be written (suppressing the argument of the demand schedules in the integral) as

$$
\begin{aligned}
T\left(p_{1}^{\prime}, p_{2}^{\prime}, p_{1}^{\prime \prime}, p_{2}^{\prime \prime}\right)= & \int_{r}\left(x_{1} d p_{1}+x_{2} d p_{2}\right) \\
& +\sum_{i=1}^{2}\left(p_{i}^{\prime}-c_{i}\right) x_{i}\left(p_{1}^{\prime}, p_{2}^{\prime}\right)
\end{aligned}
$$

over any path $r$ that connects $\left(p_{1}^{\prime}, p_{2}^{\prime}\right)$ with $\left(p_{1}^{\prime \prime}, p_{2}^{\prime \prime}\right)$, where $x_{1}\left(p_{1}^{\prime \prime}, p_{2}^{\prime \prime}\right)=x_{2}\left(p_{1}^{\prime \prime}, p_{2}^{\prime \prime}\right)=0$. In other words, the demands are zero at the tariffs $\left(p_{1}^{\prime \prime}, p_{2}^{\prime \prime}\right)$. The independence of $T\left(p_{1}^{\prime}, p_{2}^{\prime}\right)$ on the path of integration follows from the assumption of zero income effects.

The change in total surplus that would result from a movement of tariffs from $\left(p_{1}^{\prime}, p_{2}^{\prime}\right)$ to marginal costs $\left(c_{1}, c_{2}\right)$ can be written as

$$
\begin{aligned}
\Delta T= & \int_{r}\left(x_{1} d p_{1}+x_{2} d p_{2}\right) \\
& -\sum_{i=1}^{2}\left(p_{i}^{\prime}-c_{i}\right) x_{i}\left(p_{1}^{\prime}, p_{2}^{\prime}\right),
\end{aligned}
$$

where $r$ is any path from $\left(c_{1}, c_{2}\right)$ to $\left(p_{1}^{\prime}, p_{2}^{\prime}\right)$. Some possible paths of integration are shown in figure 1 . The $\Delta T$ obtained in this process is the gain in total surplus that would result if marginal cost pricing were used instead of the tariffs $\left(p_{1}^{\prime}, p_{2}^{\prime}\right)$.

Suppose we want to estimate the welfare effects associated with moving one of these tariffs (say, $p_{1}$ ) from its regulated level $\left(p_{1}^{\prime}\right)$ to marginal cost 
FIGURE 1.-PATHS OF INTEGRATION

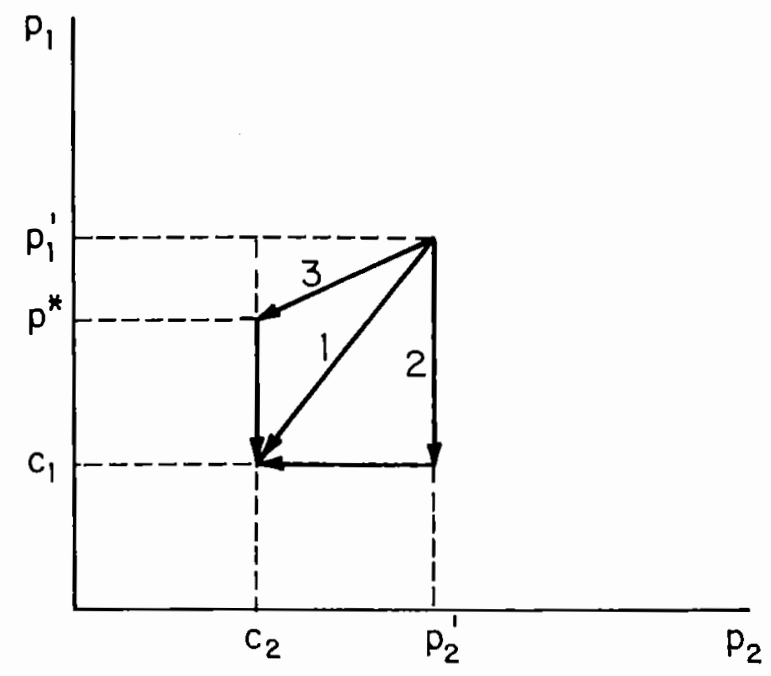

Notation:

$$
\begin{aligned}
p_{i} & =\text { tariff on mode } i \\
p_{i}^{\prime} & =\text { regulated tariff on mode } i \\
c_{i} & =\text { marginal cost on mode } i .
\end{aligned}
$$

$\left(c_{1}\right)$. Assume that under regulation in neither mode does price equal marginal cost (i.e., $p_{i}^{\prime} \neq c_{i}$, for $i=1,2)$. One way to estimate these welfare effects is to evaluate the expression $T\left(c_{1}, p_{2}^{\prime}, p_{1}^{\prime \prime}, p_{2}^{\prime \prime}\right)-$ $T\left(p_{1}^{\prime}, p_{2}^{\prime}, p_{1}^{\prime \prime}, p_{2}^{\prime \prime}\right)$, in which the first tariff is moved from $p_{1}^{\prime}$ to $c_{1}$ and the second tariff remains at $p_{2}^{\prime} \neq c_{2}$. In this case the welfare effects of mode 1 regulation cannot be evaluated without information about the change in the demand for mode 2 service that would occur as a result of the change in the first tariff. The effect of a differential change in $p_{1}$ on $T$ is estimated by

$$
\begin{aligned}
\frac{\partial T}{\partial p_{1}}= & \left(p_{1}^{\prime}-c_{1}\right) \frac{\partial x_{1}\left(p_{1}^{\prime}, p_{2}^{\prime}\right)}{\partial p_{1}} \\
& +\left(p_{2}^{\prime}-c_{2}\right) \frac{\partial x_{2}\left(p_{1}^{\prime}, p_{2}^{\prime}\right)}{\partial p_{1}} .
\end{aligned}
$$

The standard approximation of (3) for a change from $p_{1}^{\prime}$ to $c_{1}$ is

$$
\begin{aligned}
\Delta T_{1} \approx & \frac{1}{2}\left(p_{1}^{\prime}-c_{1}\right)\left[x_{1}\left(c_{1}, p_{2}^{\prime}\right)-x_{1}\left(p_{1}^{\prime}, p_{2}^{\prime}\right)\right] \\
& -\left(p_{2}^{\prime}-c_{2}\right)\left[x_{2}\left(p_{1}^{\prime}, p_{2}^{\prime}\right)-x_{2}\left(c_{1}, p_{2}^{\prime}\right)\right] .
\end{aligned}
$$

The first term on the right hand side of (4) is the dead weight loss triangle, computed using the Marshallian demand for $x_{1}$, evaluated at $p_{2}^{\prime}$. With
Figure 2.-Change IN Total SURPluS if Marginal Cost Pricing Is AdOPTED IN MARKeT 1
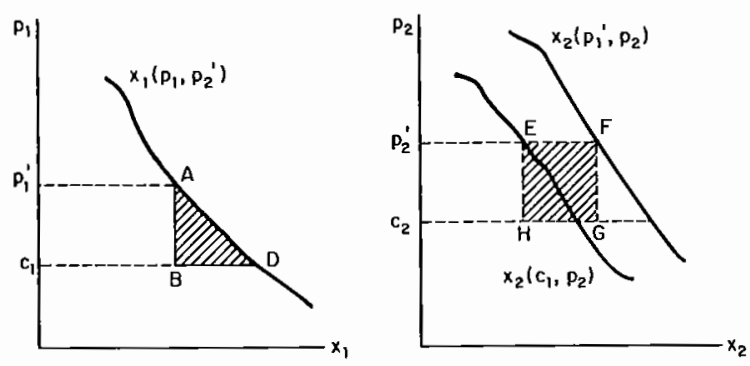

Notation:

$$
\begin{aligned}
x_{i} & =\text { quantity shipped by mode } i \\
p_{i} & =\text { tariff on mode } i \\
x_{i}\left(p_{1}, p_{2}\right) & =\text { demand curve for mode } i \\
p_{i}^{\prime} & =\text { regulated tariff on mode } i \\
c_{i} & =\text { marginal cost on mode } i
\end{aligned}
$$

constant marginal costs, the second term corresponds to the change in profits for mode 2 resulting from the change in that mode's traffic when the tariff in mode 1 is moved from $p_{1}^{\prime}$ to $c_{1}$. The total surplus change is thus depicted in figure 2 . The change in total surplus is the shaded area ABD minus the shaded area EFGH, approximated by (4). This corresponds to the vertical part of path 2 in figure 1.

To estimate the change in total surplus associated with moving both tariffs to marginal cost, path 2 (figure 1) must be completed by integrating its horizontal portion. The welfare effect of a differential change in $p_{2}$, holding $p_{1}$ constant, is

$$
\begin{aligned}
\frac{\partial T}{\partial p_{2}}= & \left(p_{1}-c_{1}\right) \frac{\partial x_{1}\left(p_{1}, p_{2}\right)}{\partial p_{2}} \\
& +\left(p_{2}-c_{2}\right) \frac{\partial x_{2}\left(p_{1}, p_{2}\right)}{\partial p_{2}}
\end{aligned}
$$

On the horizontal segment of path $2, p_{1}=c_{1}$, so that the first term of (5) is zero. Hence (5) is estimated as

$$
\Delta T_{2} \approx \frac{1}{2}\left(p_{2}^{\prime}-c_{2}\right)\left[x_{2}\left(c_{1}, c_{2}\right)-x_{2}\left(c_{1}, p_{2}^{\prime}\right)\right] .
$$

Equation (6) is the usual dead weight loss triangle, computed using the Marshallian demand schedule $x_{2}$, evaluated at $p_{1}=c_{1}$. This is depicted in figure 3 as the shaded area IJK, which, when added to area ABD minus EFGH in figure 2, approximates the total surplus gain that could be realized if marginal cost pricing were used instead of the 
Figure 3.-Change in Total Surplus if Marginal Cost PRICING Is AdOPTED IN MARKeT 2

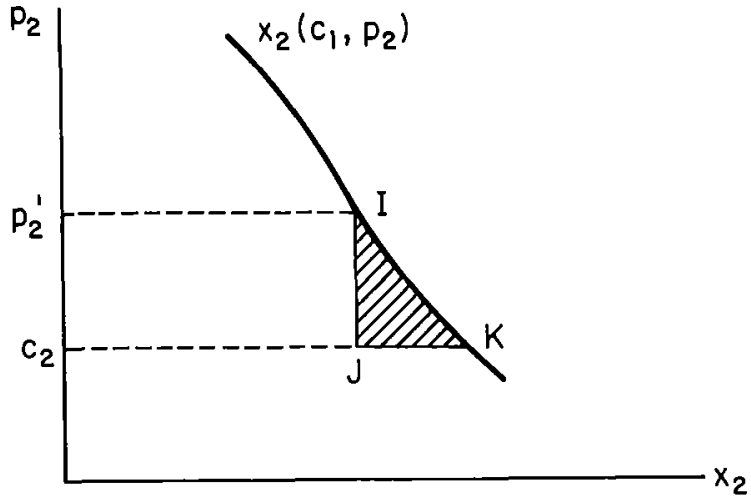

Notation:

$x_{i}=$ quantity shipped by mode $i$

$p_{i}=$ tariff on mode $i$

$x_{i}\left(p_{1}, p_{2}\right)=$ demand curve for mode $i$

$p_{i}^{\prime}=$ regulated tariff on mode $i$

$c_{i}=$ marginal cost on mode $i$.

regulated tariffs. Total surplus is maximized with marginal cost pricing, so that area ABD plus area IJK minus area EFGH must be nonnegative (area ABD minus area EFGH may be negative).

As an alternative to the use of Marshallian demand schedules, it is also possible to employ mutatis mutandis demand schedules (in which both prices vary simultaneously), shown by path 1 in figure 1 . By integrating along path 1 , the welfare loss from regulation can be estimated as

$$
\begin{aligned}
\Delta T= & \frac{1}{2}\left[x_{1}\left(c_{1}, c_{2}\right)-x_{1}\left(p_{1}^{\prime}, p_{2}^{\prime}\right)\right]\left[p_{1}^{\prime}-c_{1}\right] \\
& +\frac{1}{2}\left[x_{2}\left(c_{1}, c_{2}\right)-x_{2}\left(p_{1}^{\prime}, p_{2}^{\prime}\right)\right]\left(p_{2}^{\prime}-c_{2}\right) .
\end{aligned}
$$

The method of (7) is an alternative to summing the estimates from (4) and (6). If the approximations used to write (4), (6) and (7) are correct, both methods will produce the same estimate of the change in surplus. In practice, if the demand relationships are not exactly consistent with the approximated surplus equations, the methods will produce different estimates. In section II these methods are compared using Boyer's data.

A surprisingly common practice in transportation studies is to overlook some of the components of total surplus. Indeed, among studies using surplus analysis only Levin (1978) uses a theoretically correct path of integration. Boyer (1977),
Friedlaender (1969) and Keeler (1976) ignore intermodal effects. Friedlaender and Spady (1980) and Moore (1975) attempt to account for intermodal cross-elasticities of demand, but use an incorrect procedure. Spann and Erickson (1970) and Zerbe (1980), in estimating the welfare effects of early railroad regulation, implicitly assume zero cross-elasticity between long-haul and short-haul shipments.

In addition, some studies also incorrectly try to determine how much of the total surplus change should be attributed to each mode if both tariffs are changed to marginal costs. The method adopted is to calculate the welfare gain from deregulation in one mode by holding the other price fixed, and then to calculate the gains from deregulation in the second mode, given the new price in the first. This procedure is faulty because no such unique measure exists. For example, in figure 1, a path of integration that changed $p_{2}$ first, moving from $\left(p_{1}^{\prime}, p_{2}^{\prime}\right)$ to $\left(p_{1}^{\prime}, c_{2}\right)$ to $\left(c_{1}, c_{2}\right)$, would normally produce a different "allocation" of the welfare gains between modes than an integration along path 2 would yield, even though the totals would be the same in the absence of errors of approximation. In general, the line integral is a function of rate changes in both modes, and cannot be written separably to ascribe a unique and meaningful change in surplus to either mode individually.

A final source of error in other studies is the common assumption that total freight shipments are unaffected by tariffs. The comparative cost studies estimate the costs of regulation by reallocating actual shipments in a given year according to marginal costs and multiplying the amounts of shipments reallocated by the differences in costs between the modes. Boyer and Levin employ a logit model to estimate the market share of each mode, given tariffs in all modes. The quantity of shipments by mode is then calculated by multiplying these shares by the actual quantity of shipments- in a given year. This ignores any business gained or lost by the transportation sector as a result of changed prices; in (7), $\Delta x_{1}$ must be equal in magnitude and opposite in sign to $\Delta x_{2}$.

The assumption of perfectly inelastic total demand affects the estimated welfare effects of price changes. The quantity to be shipped by mode $i, x_{i}$, is defined to be the share, $S_{i}$, of the market shipped by that mode times the total quantity shipped by both modes. Thus, a change in $p_{1}$ can be expected 
to affect $x_{i}$ as follows:

$$
\frac{\partial x_{i}}{\partial p_{1}}=\frac{\partial S_{i}}{\partial p_{1}}\left(x_{1}+x_{2}\right)+S_{i}\left(\frac{\partial x_{1}}{\partial p_{1}}+\frac{\partial x_{2}}{\partial p_{1}}\right) .
$$

If the total ton miles of freight shipped by both modes is assumed to be constant, the second term of (8) will be zero by assumption

$$
\left(\frac{\partial x_{1}}{\partial p_{1}}+\frac{\partial x_{2}}{\partial p_{1}}=0\right) \text {. }
$$

In reality, if $p_{1}$ drops while $p_{2}$ is unchanged, one would expect the sign of the second term to be negative, since shippers might demand more transportation when one tariff is lowered. The data used to estimate the modal split equation will be from various markets with different tariffs. Hence the parameters estimated in the modal split equation will incorporate both market-elasticity and cross-elasticity effects into a model that explicitly accounts for only the latter. The predicted share of a mode after a price decrease will be a share of a quantity that reflects both elasticity effects; however, the (smaller) initial quantity will be multiplied by this new estimated share to determine the new quantity shipped by the same mode.

Thus, the inelasticity assumption will lead to an understatement of the effects of a change in $p_{1}$ on $x_{1}$ and to an overestimate of the extent to which mode 2 will be affected by a change in $p_{1}$. Further, in each case the magnitude of the effect will be most significant when the market share of the corresponding mode is large. This is apparent from (8), in which $S_{i}$ is the coefficient on the quantity effect that is assumed to be zero.

How does the inelasticity assumption affect the estimates of the change in welfare resulting from movements of tariffs in both markets to marginal costs? To answer this question, we analyze the effects of the inelasticity assumption using the method of calculation of (7). Consider an estimation of the change in $x_{i}$ that would result from a movement of both tariffs from their regulated levels to marginal cost. An approximation of this change, $\left(\Delta x_{i}\right)^{*}$, without the inelasticity assumption can be written as

$$
\left(\Delta x_{i}\right)^{*} \approx \sum_{j=1}^{2} \frac{\partial x_{i}}{\partial p_{j}}\left(c_{j}-p_{j}^{\prime}\right) ; \quad i=1,2
$$

For notational convenience, let $x_{1}+x_{2}=Q$ at $\left(p_{1}^{\prime}, p_{2}^{\prime}\right)$, and rewrite (9) as

$$
\begin{array}{r}
\left(\Delta x_{i}\right)^{*} \approx \sum_{j=1}^{2}\left[\frac{\partial S_{i}}{\partial p_{i}} Q+S_{i} \frac{\partial Q}{\partial p_{j}}\left(c_{j}-p_{j}^{\prime}\right)\right] ; \\
i=1,2 .
\end{array}
$$

From (7), the change in total surplus, $\Delta T^{*}$, without the inelasticity assumption, from moving both tariffs to marginal costs is approximately

$$
\Delta T^{*} \approx \sum_{i=1}^{2}\left(p_{i}^{\prime}-c_{i}\right)\left(\Delta x_{i}\right)^{*} .
$$

Finally, after some algebra, $\Delta T^{*}$ can be approximated as

$$
\begin{aligned}
\Delta T^{*} \approx & \frac{1}{2} \sum_{i=1}^{2}\left[\left(p_{i}^{\prime}-c_{i}\right) \sum_{j=1}^{2} \frac{\partial S_{i}}{\partial p_{j}} Q\left(c_{j}-p_{j}^{\prime}\right)\right] \\
& +\frac{1}{2}\left[\sum_{i=1}^{2} \frac{\partial Q}{\partial p_{i}}\left(c_{i}-p_{i}^{\prime}\right)\right]\left[\sum_{i=1}^{2}\left(p_{i}^{\prime}-c_{i}\right) S_{i}\right]
\end{aligned}
$$

The first term on the right hand side of (12) would be the welfare change estimated if the inelasticity assumption were valid. Denote this term by $\Delta T^{e}$. The bias introduced if the inelasticity assumption is invalid is captured by the second term on the right hand side of (12), which is denoted by $\delta$. Note that if the inelasticity assumption is valid, $\delta=0$ because $\partial Q / \partial p_{i}$ is zero.

The sign of $\delta$ must be positive whenever both regulated tariffs depart from marginal costs in the same direction, because in either case both of the bracketed components of $\delta$ are of the same sign. Thus, a larger estimate of the welfare effects of regulation would be expected if the inelasticity assumption were not imposed. The sign of $\delta$ cannot be determined purely theoretically if the regulated tariff exceeds marginal cost in one market, but is less than marginal cost in the other, for then the two bracketed components of $\delta$ may or may not have the same sign.

\section{The Effects of Invalid Paths of Integration}

In this section, the data and demand equations presented by Boyer are used to recalculate the welfare effects of regulation in 1963 along a valid path of integration. The approximations in both equation (7) and equations (4) and (6) are used. The results of these calculations are shown in table 1 . 
Table 1. - Welfare Calculations

\begin{tabular}{|c|c|c|c|c|c|c|c|c|c|c|c|c|c|}
\hline \multirow{2}{*}{$\begin{array}{l}\text { Mileage } \\
\text { Block } \\
\text { (1) }\end{array}$} & \multirow{2}{*}{$\begin{array}{c}S_{1} \text { at } \\
\left(p_{1}^{\prime}, p_{2}^{\prime}\right) \\
(2)\end{array}$} & \multicolumn{4}{|c|}{ \/Ton $\cdot$ Mile } & \multirow{2}{*}{$\begin{array}{c}1963 \\
\text { Ton } \cdot \text { Miles } \\
\text { of Traffic } \\
\text { (billions) } \\
\text { (7) }\end{array}$} & \multirow{2}{*}{$\begin{array}{c}S_{1} \text { at } \\
\left(c_{1}, p_{2}^{\prime}\right) \\
(8)\end{array}$} & \multirow{2}{*}{$\begin{array}{c}\Delta W_{4} \text { from } \\
\text { Eq. (4), } \$ \text { mil. } \\
\text { (9) }\end{array}$} & \multirow{2}{*}{$\begin{array}{c}S_{1} \text { at } \\
\left(c_{1}, c_{2}\right) \\
(10)\end{array}$} & \multirow{2}{*}{$\begin{array}{c}\Delta W_{6} \text { from } \\
\text { Eq. (6), } \$ \text { mil. } \\
\text { (11) }\end{array}$} & \multirow{2}{*}{$\begin{array}{c}\Delta W_{4}+\Delta W_{6} \\
\text { \$ mil. } \\
\text { (12) }\end{array}$} & \multirow{2}{*}{$\begin{array}{c}\Delta W_{7} \text { from } \\
\text { Eq. (7), \$ mil. } \\
\text { (13) }\end{array}$} & \multirow{2}{*}{$\begin{array}{c}\text { Boyer's } W \text { rail } \\
\$ \text { mil. } \\
\text { (14) }\end{array}$} \\
\hline & & $\begin{array}{l}p_{1}^{\prime} \\
(3)\end{array}$ & $\begin{array}{l}p_{2}^{\prime} \\
(4)\end{array}$ & $\begin{array}{l}c_{1} \\
(5)\end{array}$ & $\begin{array}{l}c_{2} \\
(6)\end{array}$ & & & & & & & & \\
\hline 25 & 0.35 & 6.14 & 19.84 & 6.64 & 18.56 & 2.63 & 0.33 & 1.0 & 0.31 & 0.3 & 1.3 & 0.9 & n.c. \\
\hline 75 & 0.36 & 3.21 & 10.41 & 2.97 & 8.45 & 7.51 & 0.38 & -3.0 & 0.32 & 4.6 & 1.6 & 2.6 & n.c. \\
\hline 150 & 0.50 & 2.69 & 6.88 & 2.00 & 5.94 & 21.09 & 0.60 & -12.9 & 0.56 & 4.3 & -8.6 & -1.6 & 4.4 \\
\hline 250 & 0.55 & 2.23 & 4.97 & 1.61 & 5.17 & 26.92 & 0.68 & 17.8 & 0.69 & 0.3 & 18.1 & 14.3 & $10.8^{\mathrm{a}}$ \\
\hline 350 & 0.60 & 2.11 & 4.00 & 1.44 & 4.96 & 17.62 & 0.75 & 34.7 & 0.80 & 4.1 & 38.8 & 28.7 & 11.8 \\
\hline 450 & 0.66 & 2.05 & 3.98 & 1.37 & 4.86 & 22.32 & 0.80 & 37.5 & 0.81 & 0.7 & 38.2 & 31.3 & 13.7 \\
\hline 550 & 0.68 & 2.11 & 3.99 & 1.29 & 4.81 & 22.05 & 0.83 & 41.5 & 0.86 & 2.4 & 43.9 & 32.5 & 16.3 \\
\hline 700 & 0.71 & 1.87 & 3.45 & 1.24 & 4.73 & 40.01 & 0.84 & 82.8 & 0.89 & 12.8 & 95.6 & 68.8 & 22.7 \\
\hline 900 & 0.76 & 1.71 & 3.24 & 1.18 & 4.68 & 33.15 & 0.86 & 57.0 & 0.91 & 11.7 & 68.7 & 49.0 & 13.2 \\
\hline 1100 & 0.79 & 1.74 & 3.23 & 1.16 & 4.65 & 18.93 & 0.89 & 31.6 & 0.93 & 5.6 & 37.2 & 34.2 & 7.7 \\
\hline 1350 & 0.83 & 1.75 & 2.59 & 1.13 & 4.62 & 21.03 & 0.93 & 49.2 & 0.96 & 6.4 & 55.6 & 36.2 & 8.5 \\
\hline 1750 & 0.86 & 1.68 & 2.47 & 1.11 & 4.59 & 39.30 & 0.94 & 76.2 & 0.97 & 12.1 & 88.3 & 58.1 & $12.3^{\mathrm{a}}$ \\
\hline Total & & & & & & & & 413.4 & & 65.3 & 478.7 & 355.0 & $121.4^{\mathrm{a}}$ \\
\hline
\end{tabular}

Sources:Col. 2 from Boyer (table 4. column 9)

Col. 3 from Boyer (table 4. column

Col. 4 from Boyer (table 4, column 6 )

Col. 5 from Boyer (table 4, column 2 )

Col. 6 from Boyer (table 4, column 3 )

Cols. 8-13, calculated as described in text

Col. 14 from Boyer (table 4, column 11), where n.c. means not calculated.

${ }^{2}$ Correction of Boyer's reported numbers using his methodology and data. 
The demand equation that Boyer used to calculate welfare effects was as follows:

$$
\Delta \ln \frac{S_{1}}{S_{2}}=-4.15\left[\left(\frac{p_{1}}{p_{2}}\right)_{a}-\left(\frac{p_{1}}{p_{2}}\right)_{b}\right]
$$

where

$$
\begin{aligned}
i= & \text { a modal index, } 1 \text { for rail, } 2 \text { for motor } \\
& \text { carriers } \\
S_{i}= & \text { the share of traffic for mode } i, \text { where } \\
& S_{1}+S_{2}=1 \\
p_{i}= & \text { the tariff for mode } i \\
b= & \text { the state before tariffs are changed } \\
a= & \text { the state after tariffs are changed. }
\end{aligned}
$$

In table 1 , the welfare change associated with the rail rate change (with no change in the motor carrier rate) is calculated from (4) and reported as $\Delta W_{4}$ in column 9. The estimated welfare effect of railroad regulation is $\$ 413.4$ million, which is much larger than Boyer's estimate (column 14).

To complete the estimate of the welfare effects of regulation for both modes, we carry out the calculation of equation (6), reported as $\Delta W_{6}$ in column $11 .^{3}$ Column 11 is the incremental gain from deregulating trucks, given that railroads have been deregulated. The total welfare effect of regulation, the sum of columns 9 and 11 (shown in column 12 ), is $\$ 478.7$ million. ${ }^{4}$

In column 13 we use the mutatis mutandis demand schedules of equation (7) to calculate an alternative estimate of the welfare loss from regulation. This estimate is $\$ 355$ million.

Boyer's estimate of the total cost of regulation is much less than either of ours. The source of the difference is that he overlooks the effect of railroad deregulation on truck profits. This biases his result downward because, according to his data, truck prices are below marginal cost for long-distance shipping, so that truck profits increase if they lose market share in these mileage blocks. This we view as highly implausible, although we use his data in our calculations to compare our welfare estimates with his.

\footnotetext{
${ }^{3}$ Column 10 differs from Boyer's predicted market shares in column 10 of table 4 of his paper. Our calculations avoid the error made by Boyer that is discussed in footnote 10 of Levin's paper.

${ }^{4}$ Each entry in column 12 should be positive. An anomalous result that cannot be correct appears in the 150 mileage block. This could occur because of approximation error or because there are errors in the estimates of the demand structure not explored in this paper.
}

The difference in our two estimates arises from the error introduced by using the standard approximations of the surplus equations. The term $\left(p_{i}^{\prime}-c_{i}\right)$ is as much as $35 \%$ of $p_{i}^{\prime}$ for rails and $80 \%$ for trucks in some mileage blocks. Thus, it is stretching matters to regard the change in tariffs as "small" for purposes of approximation.

\section{The Effects of the Inelastic Demand Assumption}

This section explores the empirical significance of the assumption that the total market demand for surface freight transportation is perfectly inelastic with respect to all tariffs. Direct estimation of the effects of this assumption would require econometric estimates of properly specified modal demand equations that, among other things, included the tariffs for all modes in the demand equation of each. We have not attempted this. Instead, we have used Boyer's data to estimate the sensitivity of his estimates of welfare loss to alternative assumptions about the price elasticity of market demand. Consider two effects on shipments in mode $i$ due to a change in its price, $p_{i}$ : the change in mode $i$ 's share of total shipping, and the change in mode $i$ 's shipments owing to a change in total shipping. Let $s$ be the proportionality factor between these quantities:

$$
\frac{\partial Q}{\partial p_{i}}=s \frac{\partial S_{i}}{\partial p_{i}} Q .
$$

The right-hand side of (14) can be substituted for the term $\partial Q / \partial p_{i}$ in (12), and the data in table 1 can then be used to estimate the change in surplus as a function of $s$.

Of course, $s$ is closely related to the elasticity of total shipments with respect to a change in modal prices. If both sides of (14) are divided by the ratio of $Q$ to $p_{i}$, the result is

$$
e_{i}=s S_{i} e_{i s}
$$

where $e_{i s}$ is the elasticity of mode $i$ 's share with respect to $p_{i}$ and $e_{i}$ is the elasticity of total demand with respect to $p_{i}$.

Values of $S_{i} e_{i s}$ can be calculated from table 1, and tend to lie in the range -0.2 to -0.5 for rails, and between -0.05 and -0.3 for trucks. Thus, if $e_{i}$ were -0.1 (e.g., a $10 \%$ change in $p_{i}$ causes a $1 \%$ net change in total shipments), $s$ would fall in the range of 0.2 to 0.4 for rails and between 0.3 and 2.5 for trucks. Alternatively, a value of $s$ of unity 
TABle 2. - Additional Welfare EfFects if Demand Elasticity Nonzero (FIGURE IN \$ MILLIONS)

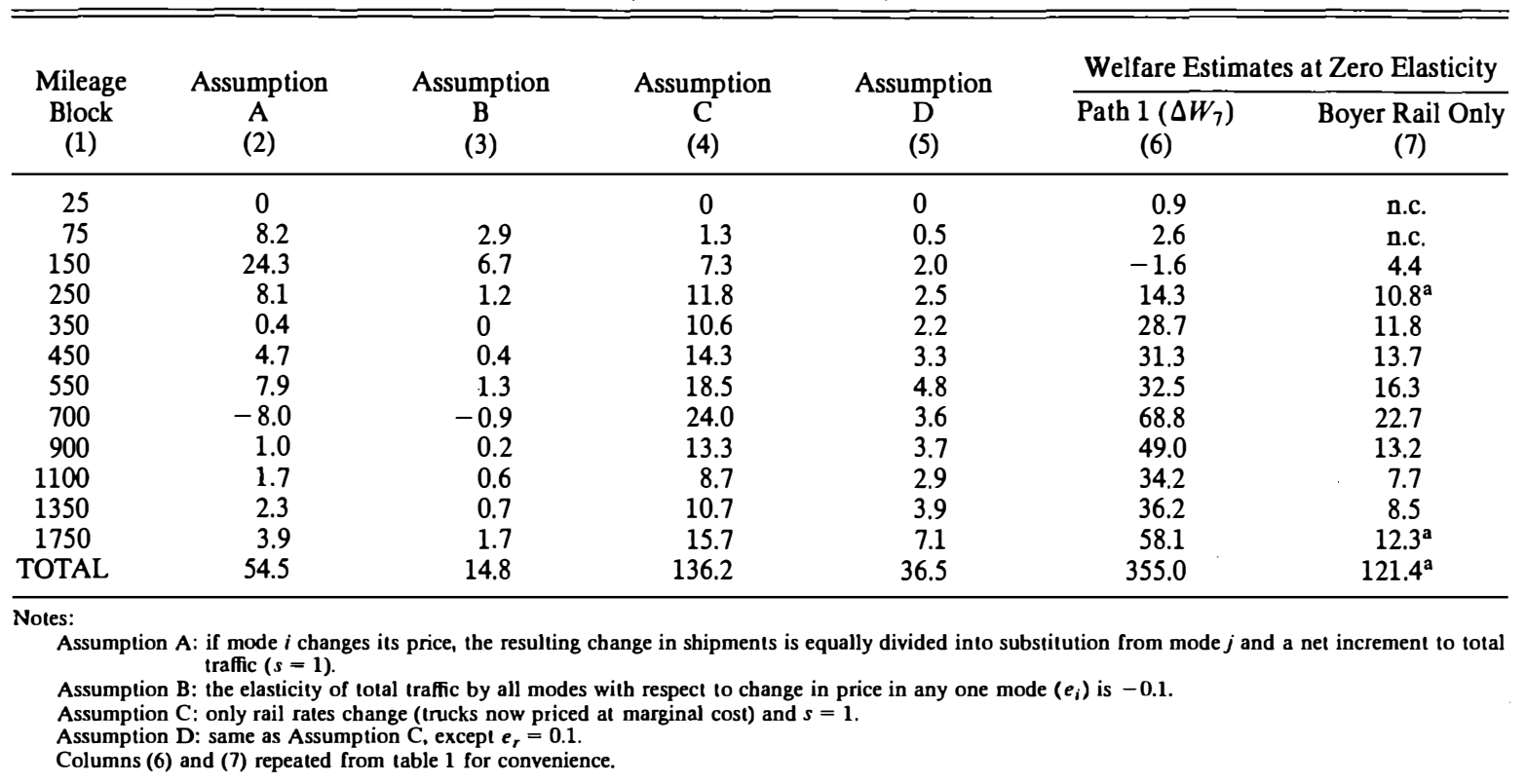

implies a value of $e_{i}$ of about -0.35 . These values are roughly consistent with the elasticities reported by Moore. ${ }^{5}$

We have calculated the value of the last term in (12) - the magnitude of the bias from overlooking the net increments to shipping from a change in modal prices-using Boyer's data. The results are shown in table 2 . If for each mileage block one selects a value of $s$ that makes $e_{i}$ equal to -0.1 , the estimated welfare gain from marginal cost pricing increases by approximately $\$ 15$ million (column (3)). If instead a value of $s$ equal to unity is applied for all calculations, the estimated welfare gain from marginal cost pricing is increased by $\$ 55$ million (column (4)). These calculations are substantially affected by the peculiar feature of Boyer's data that truck prices are below marginal costs for most blocks. If regulated truck prices are assumed to be equal to marginal cost, and if $e_{i}$ is assumed to be -0.1 , then the additional welfare

\footnotetext{
${ }^{5}$ Moore reports estimates of demand functions for trucks and rails that have cross-elasticities of demand of about 0.9 for both modes, and own-price elasticities of -1.8 for trucks and -0.9 for rails. With about $60 \%$ of shipments in ton-miles moving by rail, this suggests that one-third of the new business generated by a reduction in rail tariffs is a net increase in total shipment (e.g., $s=0.5$ ), whereas about one-fourth of trucking gains from a price reduction would be net new shipments (e.g., $s=0.33$ ). These estimates are, of course, extremely crude, being based on single-equation demand models that aggregate over all types of commodities and shipping distances.
}

gain from prices equal to marginal costs in rails is $\$ 36$ million (column (5)). If $s$ is assumed to be unity in all blocks, the additional gain is $\$ 136$ million (column (4)). As is apparent from table 2, these magnitudes are nontrivial fractions of Boyer's estimates of the welfare effects of regulation.

\section{Conclusions}

This paper has investigated methods for estimating the total welfare loss from the regulation of surface freight transportation. Numerous previous studies have been found to use invalid methods for calculating this loss. We have used methodologically correct procedures to estimate the welfare loss from regulation, using Boyer's data and market share estimation technique. Three principal findings emerge. First, the choice of a correct path of integration increased the estimated welfare loss by a factor of three or four. Second, the choice of a path of integration substantially affects the estimated welfare loss because of the errors introduced by using the standard formulas to approximate surplus equations over relatively large changes in prices and quantities. Third, the assumption that the total quantity of freight shipped by all modes is perfectly inelastic caused an underestimate of the welfare costs of regulation that is substantial. When the first and last effects are 
accounted for, the estimate of the annual welfare loss of surface freight transportation is increased from $\$ 121$ million to upwards of $\$ 500$ million.

\section{REFERENCES}

Boyer, Kenneth D., "Minimum Rate Regulation, Modal Split Sensitivities, and the Railroad Problem," Journal of Political Economy 85 (3) (1977), 493-512.

Friedlaender, Ann F., The Dilemma of Freight Transport Regulation (Washington, D.C.: Brookings Institution, 1969).

Friedlaender, Ann F., and Richard Spady, Freight Transport Regulation: Equity, Efficiency and Competition in the Rail and Trucking Industries (Cambridge, MA: MIT Press, 1980).

Harbeson, R. W., "Towards Better Resource Allocation in Transport," Journal of Law and Economics 12 (Oct. 1969), 321-338.
Keeler, Theodore E., "On the Economic Impact of Railroad Freight Regulation," Processed, 1976.

Levin, Richard C., "Allocation in Surface Freight Transportation: Does Rate Regulation Matter?" Bell Journal 9 (Spring 1978), 18-45.

Moore, Thomas Gale, "Deregulating Surface Freight Transportation," in Almarin Phillips (ed.), Promoting Competition in Regulated Markets (Washington, D.C.: Brookings Institution, 1975).

Peck, M. J., "Competitive Policy for Transportation?" in Almarin Phillips (ed.), Perspectives on Antitrust Policy (Princeton: Princeton University Press, 1965), 244-272.

Spann, Richard, and Edward W. Erickson, "The Economics of Railroading: The Beginning of Cartelization and Regulation," Bell Journal of Economics 1 (Autumn 1970), 227-244.

Zerbe, Richard O., "The Costs and Benefits of Early Regulation of the Railroads," Bell Journal of Economics 11 (Spring 1980), 343-350. 